\title{
Interactions in PEG/Aerosil ${ }^{\circledR}$ and PLA/Aerosil ${ }^{\circledR}$ composites described by $I G C$-determined Flory-Huggins $\chi_{23}$ parameter
}

\author{
Kasylda Milczewska • Adam Voelkel • Katarzyna Piędzia
}

Received: 15 July 2013 / Accepted: 13 February 2014 / Published online: 11 March 2014

(C) The Author(s) 2014. This article is published with open access at Springerlink.com

\begin{abstract}
The magnitude of the interactions between two phases may be deduced from results collected by various experimental techniques. One of them is Inverse Gas Chromatography $(I G C) . I G C$ is an extension of conventional gas chromatography in which a non-volatile material to be investigated is immobilized on a column. Parameters determined during $I G C$ experiments may be successfully used in the characterization of polymers and their blends, composites and fillers as well as other materials, quantification of the interactions between the components of a polymer's mixture including the interactions between polymeric components and filler surface. Authors propose to express the magnitude of filler-polymer interactions by using the modified procedure of the determination of Flory-Huggins $\chi_{23}^{\prime}$ parameter. It was calculated from retention data of test solutes collected during inverse gas chromatographic experiments. Here, this method was applied for characterization of a series of poly(ethylene glycol) 10,000 (PEG) and poly(L-lactide) (PLA) $(59,000)$ compositions with Aerosil ${ }^{\circledR} 200 \mathrm{~V}$ (AR_200). The usefulness of some methods to eliminate dependence of $\chi_{23}^{\prime}$ on the type of test solute was examined and discussed.
\end{abstract}

Keywords $I G C \cdot$ Flory-Huggins parameter $\cdot$ Polymer-filler interaction

K. Milczewska $(\triangle) \cdot$ A. Voelkel $\cdot$ K. Piędzia

Poznan University of Technology, Institute of Chemical Technology

and Engineering, Pl. M. Skłodowskiej-Curie 2, 60-965 Poznań,

Poland

e-mail: Kasylda.Milczewska@put.poznan.pl

\section{Introduction}

Polymer blends are a new class of materials needed to replace heavy metal alloys. Blending of polymers is a fast and inexpensive route to obtaining this class of materials [1].

Composite materials (polymers with inorganic fillers) play an important role in many fields of science. Addition of filler lowers the cost and also improves the tensile strength of the base resin. The strength of the interactions between components of the composite is the key factor in polymer materials characterization. Filler content, chemical characteristics of the components, and filler characteristics significantly influence the rheological and mechanical properties of the polymer composites. Also any change in the polymer-filler interactions affects the properties of the composition.

A variety of experiments are being used to determine material compatibility. Only a few techniques can give quantitative information about the change of free energy when mixing two components. One of them is inverse gas chromatography [2]. During the years this technique has become an accurate, reliable, and fast method for physicochemical characterization of polymer systems. The properties of the examined material are deduced from the retention data of test solutes of different chemical natures. Retention parameters depend on the magnitude of interactions between test solutes and examined material, e.g. a polymer blend playing the role of the stationary phase in a chromatographic column. Retention data are further used for calculation of physicochemical characteristics of various materials.

The usefulness of $I G C$ for determining polymer-small molecule interactions is well established. Experimentally determined retention parameters are easily recalculated into Flory-Huggins parameters, using the equation [3]:

$$
\chi_{12(3)}^{\infty}=\ln \left(\frac{273.15 \cdot R}{p_{1}^{o} \cdot V_{g} \cdot M_{1}}\right)-\frac{p_{1}^{o}}{R \cdot T} \cdot\left(B_{11}-V_{1}\right)+\ln \left(\frac{\rho_{1}}{\rho_{2(3)}}\right)-\left(1-\frac{V_{1}}{V_{2(3)}}\right)(1)
$$


where: 1 denotes the solute, and 2 or 3 denotes the examined material (polymer or filler, accordingly). $\mathrm{M}_{1}$ is the molecular weight of the solute; $\mathrm{p}_{1}^{o}$ is the saturated vapour pressure of the solute, and $\mathrm{B}_{11}$ is the second virial coefficient of the solute. $\mathrm{V}_{i}$ is the molar volume; $\rho_{\mathrm{i}}$ is the density. $\mathrm{R}$ is the gas constant, and $\mathrm{V}_{\mathrm{g}}$ is the specific retention volume.

In the case of the mixture (e.g. polymer-filler composition) Eq. (1) could be rearranged into $[4,5]$ :

$\chi_{1 m}^{\infty}=\ln \left(\frac{273.15 \cdot R}{p_{1}^{o} \cdot V_{g} \cdot M_{1}}\right)-\frac{p_{1}^{o}}{R \cdot T} \cdot\left(B_{11}-V_{1}\right)+\ln \left(\frac{\rho_{1}}{\rho m}\right)-\left(1-\frac{V_{1}}{V_{2}}\right) \cdot \varphi_{2}-\left(1-\frac{V_{1}}{V_{3}}\right) \cdot \varphi_{3}$

where $\varphi_{2}$ and $\varphi_{3}$ are the volume fractions of polymer and filler, while index $m$ means a composition.

The interaction between the two components of composition is expressed in terms of $\chi_{23}^{\prime}$ calculated from $[6,7]$ :

$\chi_{23}^{\prime}=\frac{\chi_{23}^{\infty} \cdot V_{1}}{V_{2}}=\frac{1}{\varphi_{2} \cdot \varphi_{3}} \cdot\left(\ln \frac{V_{g, m}}{W_{2} \cdot \nu_{2}+W_{3} \cdot \nu_{3}}-\varphi_{2} \cdot \ln \frac{V_{g, 2}}{\nu_{2}}-\varphi_{3} \cdot \ln \frac{V_{g, 3}}{\nu_{3}}\right)$

Here, the second subscript of $V_{g}$ identifies the nature of the column.

To obtain $\chi_{23}^{\prime}$ for a polymer blend or composition utilizing $I G C, \chi_{12}^{\infty}$ values for all components have to be known. Therefore, three columns are usually prepared: two for single components and the third one for a composition of the two components used. A further three columns containing different compositions of components can also be prepared if the effect of the weight fraction of the mixture on the examined property needs to be explored. These columns should be studied under identical conditions of column temperature, carrier gas flow rate, inlet pressure of the carrier gas, and with the same test solutes [8].

A large positive value indicates the absence of or negligible interactions between components; a low value indicates favourable interactions, while a negative value indicates strong interactions. Values of Flory-Huggins $\chi_{23}^{\prime}$ parameter depend on the chemical structure of the solute, and it is a common phenomenon, although not allowed by the theory [9]. It has been interpreted as a result of preferential interactions of the test solute with one of two components. Deshpande et al. [10] applied this technique for the determination of thermodynamic interactions between components of a mixture of polymer and nonpolymeric compound. Su et al. [11] used this technique to measure the interaction parameter of poly(vinyl chloride) (PVC) and dioctyl phthalate as a plasticizer to study their compatibility. Later, this method was also used to measure the compatibility of polymer blends. However, many studies have shown that the polymer-polymer interaction parameters determined by this technique depend on the probes used. Hsu and Prausnitz and Patterson and coworkers suggested that the compatibility of polymeric components in solution should reflect not only the interaction between the components themselves, that is, $\chi_{23}^{\prime}$, but also the difference in the strengths of the polymer-probe interactions, that is: $\Delta \chi=\left|\chi_{12}-\chi_{13}\right|$. They called it the $\Delta \chi$ effect, and a large $\Delta \chi$ value, in addition to a high $\chi_{23}^{\prime}$ value, suggests incompatibility.

Deshpande and Farooque observed probe dependency and tried to develop a method to evaluate probe-independent interactions [12].

Milczewska and Voelkel [7] discussed some of the methods of evaluating probe-independent interaction parameters. One of the solutions may be a procedure proposed by Zhao and Choi $[4,5]$. The authors proposed to use 'common reference volume' $\left(V_{o}\right)$, which eliminates the problem. For the reference volume, they used molar volume of the smallest repeated unit of polymer. Their definition of $\chi$ differed form the traditional definition by the ratio of the reference volume to the probe volume $\left(\mathrm{V}_{\mathrm{o}} / \mathrm{V}_{1}\right)$. When a common reference volume was used, the data conformed to the ternary version of the FloryHuggins lattice theory, and unique $\chi_{23}$ values were obtained.

Zhao and Choi demonstrated that by selecting a proper common reference volume for analyzing IGC data, one can yield reliable solvent-independent $\chi_{23}$, so long as the solvents used satisfy the zero $\Delta \chi$ criterion.

Flory-Huggins parameter for blends can be calculated from the equations:

$\chi_{1 m}=\frac{V_{o}}{V_{1}} \cdot\left(\ln \frac{273.15 \cdot R}{M_{1} \cdot V_{g} \cdot p_{1}^{o}}-1+\left(1-\frac{V_{1}}{V_{2}}\right) \cdot \varphi_{2}+\left(1-\frac{V_{1}}{V_{3}}\right) \cdot \varphi_{3}-\left(\frac{B_{11}-V_{1}}{R \cdot T}\right) \cdot p_{1}^{o}\right)$

and

$\chi_{1 m}=\varphi_{2} \cdot \chi_{12}+\varphi_{3} \cdot \chi_{13}-\varphi_{2} \cdot \varphi_{3} \cdot \chi_{23}^{\prime}$

Equation (5) predicts that a plot of $\chi_{1 m}$ versus $\left(\varphi_{2} \cdot \chi_{12}+\varphi_{3}\right.$ - $\left.\chi_{13}\right)$ will give a straight line with a slope of 1 and an intercept of $-\varphi_{2} \cdot \varphi_{3} \cdot \chi_{23}^{\prime}$.

Table 1 Compositions and used symbols

\begin{tabular}{lll}
\hline $\begin{array}{l}\text { Used symbol } \\
\text { A-PEG/A-PLA }\end{array}$ & $\begin{array}{l}\text { Aerosil-PEG } \\
\text { Weight fractions [g] }\end{array}$ & $\begin{array}{l}\text { Aerosil-PLA } \\
\text { Weight fractions [g] }\end{array}$ \\
\hline $0-1$ & $0.00-2.00$ & $0.00-1.00$ \\
$1-1$ & $1.00-1.00$ & $0.50-0.50$ \\
$2-1$ & $1.35-0.65$ & $0.68-0.32$ \\
$3-1$ & $1.50-0.50$ & $0.75-0.25$ \\
$4-1$ & $1.60-0.40$ & $0.80-0.20$ \\
$5-1$ & $1.66-0.34$ & $0.88-0.12$ \\
\hline
\end{tabular}


Fig. 1 Values of $\chi_{1 m}^{\infty}$ parameter for compositions with PEG at $353 \mathrm{~K}$

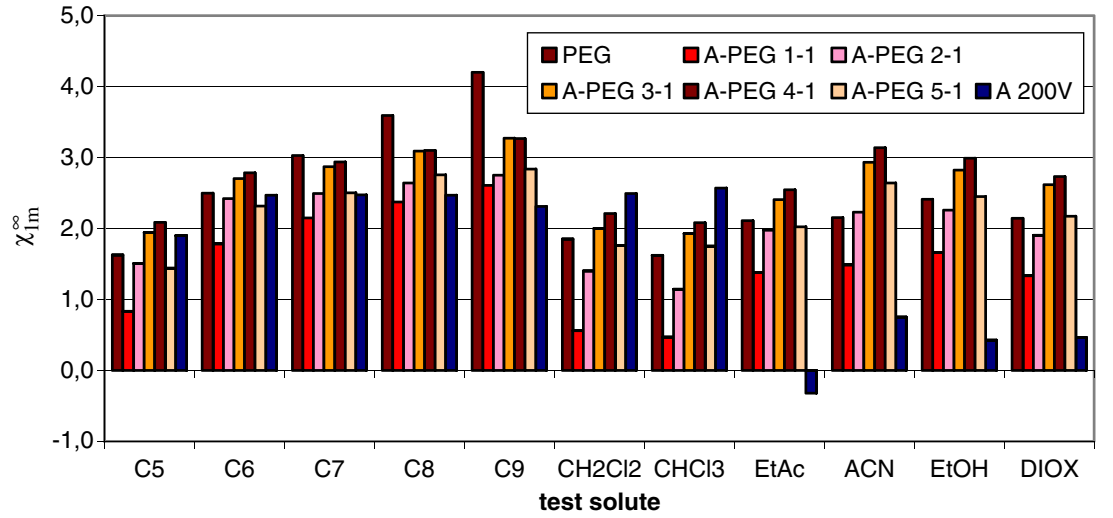

J. C. Huang [13] and R. Deanin [14] rearranged Eq. (5) into the following form:

$\frac{\chi_{1 m}}{V_{1}}=\frac{\varphi_{2} \cdot \chi_{12}+\varphi_{3} \cdot \chi_{13}}{V_{1}}-\frac{\varphi_{2} \cdot \varphi_{3} \cdot \chi_{23}^{\prime}}{V_{2}}$

The polymer-polymer interaction term can be determined from the intercept at $\left(\frac{\varphi_{2} \cdot \chi_{12}+\varphi_{3} \cdot \chi_{13}}{V_{1}}\right)=0$. This modification provided smaller standard deviations for the slope and the polymer-polymer interaction parameter [15]. J. C. Huang [16] presented some of the constraints of the models used. He noticed that the IGC technique couldn't be used in immiscible systems, because the equation of the parameter was derived based on the assumption of miscible components (blends). However, two different monomers can be brought together into a one-component system by copolymerization. So the interaction parameters between solutes and copolymers should follow a trend intermediate between the two homopolymers.

Flory-Huggins parameters from basic procedures for such types of systems were calculated successfully [17, 18].

The aim of this work was to present the possibility of applying the thermodynamic relations determined by $I G C$ for polymer blends to polymer-inorganic filler mixtures. The authors proposed to use Zhao-Choi's and Huang's procedures to determine interaction parameters in polymer-filler systems.

\section{Materials}

$I G C$ experiments were used to examine the interactions of polymer-filler systems containing poly(ethylene glycol) (PEG) (average molar mass $\sim 10,000 \mathrm{~g} \cdot \mathrm{mol}^{-1}$ ) and poly(Llactide) (PLA) $\left(55,000 \mathrm{~g} \cdot \mathrm{mol}^{-1}\right)$. Polymers (supplied from Sigma Aldrich) were mixed with hydrophilic fumed silica Aerosil ${ }^{\circledR} 200$ V (A) [19] (delivered from Evonik Industries). Detailed compositions of tested formulations are shown in Table 1.

\section{Experimental conditions}

Measurements were carried out with the use of Chrom5 (Kovo, Czech. Rep.) gas chromatograph equipped with FID. Teflon columns, $50 \mathrm{~cm} \times 0.3 \mathrm{~mm}$ I.D., were packed with the support coated with polymer or filled polymer. Polymers,
Fig. 2 Values of $\chi_{1 m}^{\infty}$ parameter for compositions with PLA at $353 \mathrm{~K}$

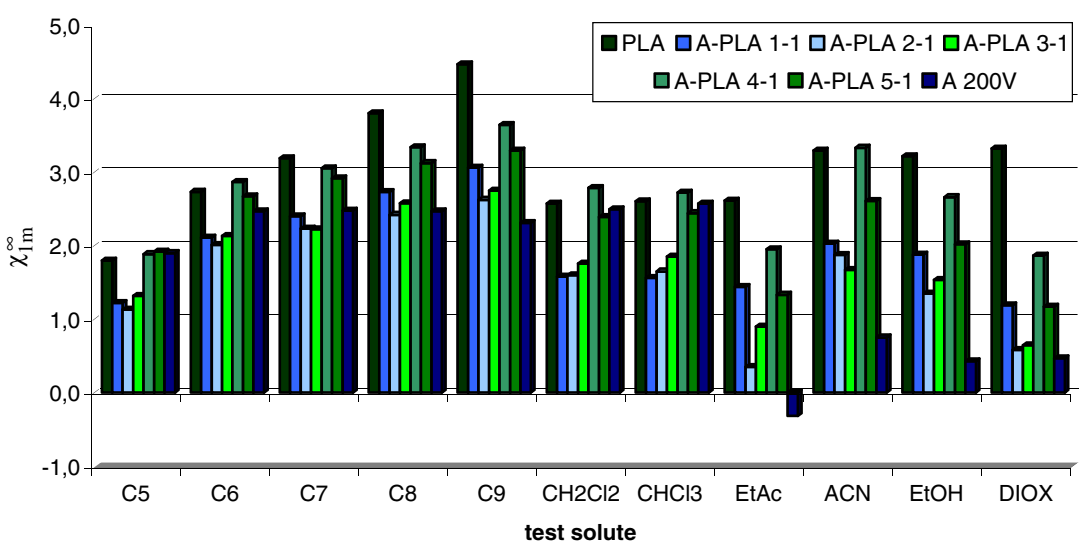


Fig. 3 Values of $\chi_{23}^{\prime}$ parameter for A-PEG 4-1 composition

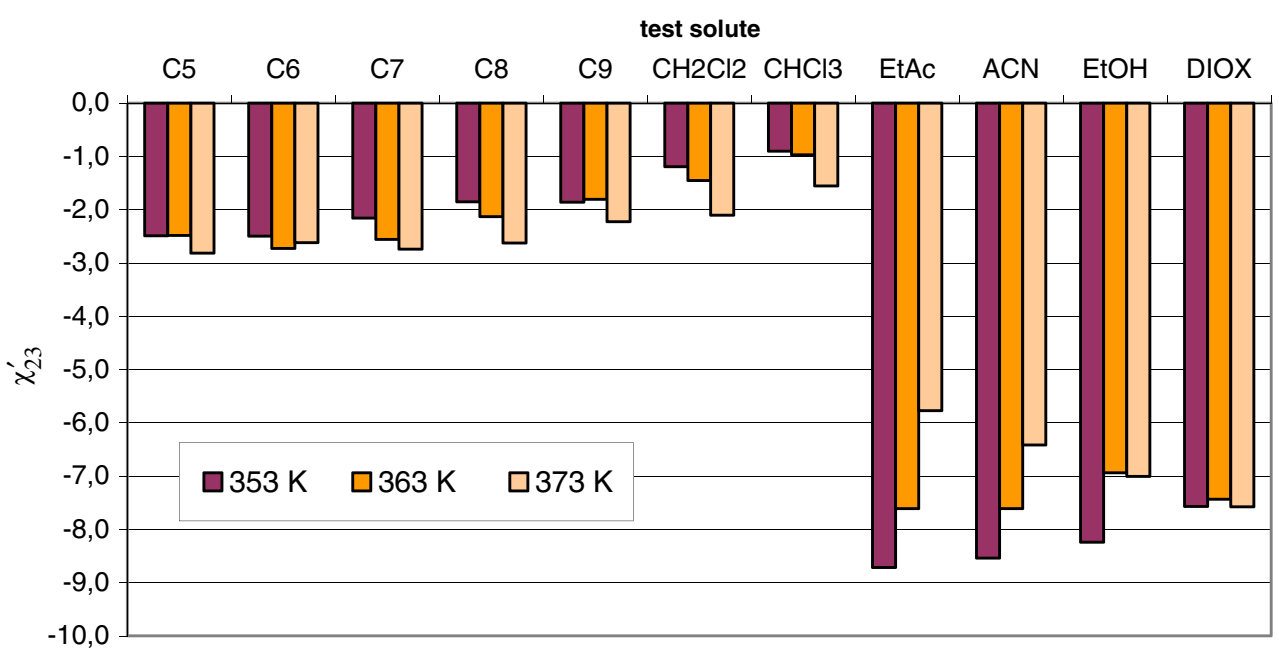

filler and compositions were mixed with glass beads at $1 \mathrm{wt} \%$ loading. The following compounds were used as test solutes: pentane (C5), hexane (C6), heptane (C7), octane (C8), nonane (C9), methylene chloride $(\mathrm{CH} 2 \mathrm{Cl} 2)$, chloroform $(\mathrm{CHCl3})$, ethyl acetate $(\mathrm{EtAc})$, acetonitrile $(\mathrm{ACN})$, ethanol $(\mathrm{EtOH})$, and 1,4-dioxane (DIOX). Dry helium with a flow rate of $15 \mathrm{ml} / \mathrm{min}$ was used as a carrier gas. The investigated materials were mixed homogeneously with the glass beads. Measurements were carried out at infinite dilution, which means that a very small amount of the test solutes was injected onto the chromatographic column filled with the examined material. All columns were conditioned overnight at the flow rate and temperature used later during IGC experiments. Retention parameters of test solutes (retention time and volume) were used to calculate values of physicochemical parameters characterizing the examined materials.

\section{Results}

Flory-Huggins $\chi_{1 m}^{\infty}$ and $\chi_{23}{ }^{\prime}$ parameters

Values of Flory-Huggins parameter $\chi_{1 \mathrm{~m}}^{\infty}$ were calculated from Eq. (2) for all investigated compositions. All the data are positive, but in all systems we can find solute for which the composition is slightly miscible (Figs. 1 and 2). The strongest interactions with test solute were observed for compositions A-PEG 1-1 and A-PLA 2-1. Aerosil also strongly interacts with the test solutes - significantly with ethyl acetate. Lower values than for alkanes were obtained for the polar probes. The best solvent (the strongest solvent-composition interaction) for both series of compositions is ethyl acetate.

Flory-Huggins parameter $\chi_{23}^{\prime}$ indicates the magnitude of interactions between components of the composition. In compositions with PEG (Fig. 3), for almost all proportions,
Fig. 4 Values of $\chi_{23}^{\prime}$ parameter for A-PLA 1-1 composition

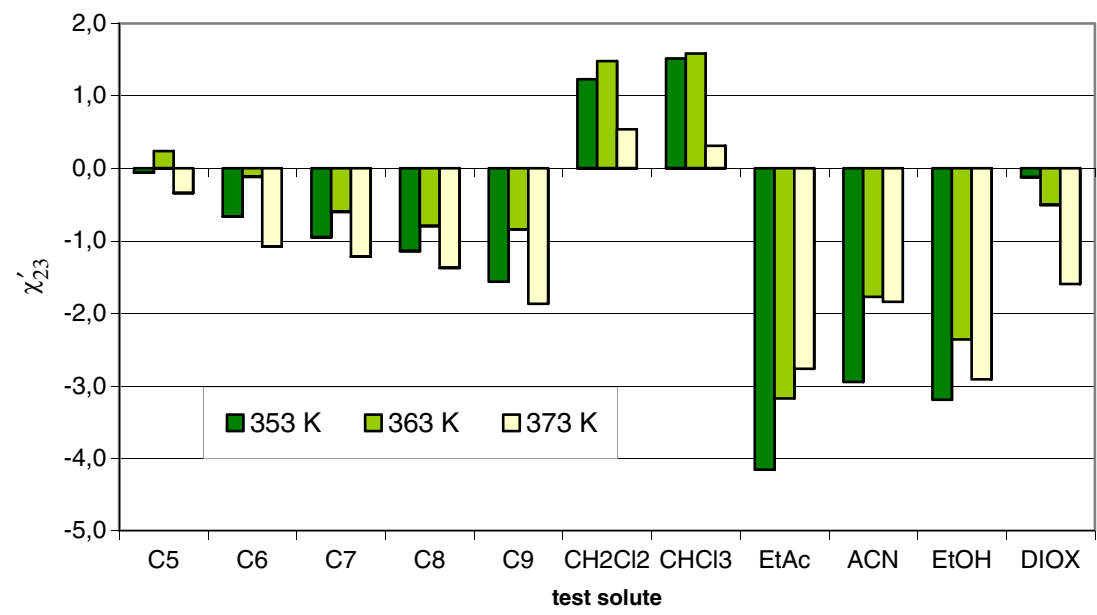


Table 2 Values of $\chi_{23}^{\prime}$ calculated from Zhao-Choi procedure for PEG composites

\begin{tabular}{lrrr}
\hline$\chi_{23}^{Z C}$ & $353 \mathrm{~K}$ & $363 \mathrm{~K}$ & \multicolumn{1}{l}{$373 \mathrm{~K}$} \\
\hline A-PEG 1-1 & $-1.26 \mathrm{E}-03$ & $-8.25 \mathrm{E}-04$ & $-6.28 \mathrm{E}-04$ \\
A-PEG 2-1 & $-8.79 \mathrm{E}-04$ & $-3.23 \mathrm{E}-04$ & $-1.43 \mathrm{E}-04$ \\
A-PEG 3-1 & $1.26 \mathrm{E}-04$ & $1.79 \mathrm{E}-05$ & $-3.95 \mathrm{E}-04$ \\
A-PEG 4-1 & $4.66 \mathrm{E}-04$ & $9.86 \mathrm{E}-04$ & $1.67 \mathrm{E}-03$ \\
A-PEG 5-1 & $-9.15 \mathrm{E}-04$ & $-4.66 \mathrm{E}-04$ & $3.05 \mathrm{E}-04$ \\
\hline
\end{tabular}

Correlation coefficient higher than $\mathrm{R}^{2}=0.94$

negative values of $\chi_{23}^{\prime}$ were obtained. In a series of A-PLA (Fig. 4) compositions, only the 1-1 Aerosil-PLA mixture is characterized by some negative $\chi_{23}^{\prime}$ values. The lowest values of $\chi_{23}^{\prime}$ are obtained for polar probes. Column temperature also influences the values of determined parameters. $\chi_{23}^{\prime}$ values for alkanes decreased with increasing temperature, but increased for polar probes.

Because of $\chi_{23}^{\prime}$ probe dependency, we used the procedures of Zhao-Choi and Huang for calculation of soluteindependent $\chi_{23}^{\prime}$.

\section{Zhao-Choi procedure}

For all compositions, values of the parameter $\chi_{23}^{\prime}$ were calculated from the procedure of Zhao-Choi (Eq. 4 and 5). As a 'reference volume', we used molar volume of repeated unit of polymers (in the case of PEG, it was $\mathrm{V}_{\mathrm{o}}=55.8$ and, for PLA $\left.\mathrm{V}_{\mathrm{o}}=74.5\left[\mathrm{~cm}^{3} / \mathrm{mol}\right]\right)$. Results are presented in the Tables 2 and 3.

Almost all $\chi_{23}^{Z C}$ values are slightly negative (with the exceptions of A-PEG 3-1 and 4-1), which may suggest the existence of strong interactions in these compositions. $\chi_{23}^{Z C}$ value increases with the increasing of the filler content in APEG compositions. $\chi_{23}^{Z C}$ values are smaller for A-PLA series than for A-PEG composites. The weakest interactions in APLA composities were found for 5-1 and 4-1; the highest

Table 3 Values of $\chi_{23}^{\prime}$ calculated from Zhao-Choi procedure for PLA composites

\begin{tabular}{llll}
\hline$\chi_{23}^{Z C}$ & $353 \mathrm{~K}$ & $363 \mathrm{~K}$ & $373 \mathrm{~K}$ \\
\hline A-PLA 1-1 & $-5.24 \mathrm{E}-04$ & $-5.91 \mathrm{E}-04$ & $-3.90 \mathrm{E}-04$ \\
A- PLA 2-1 & $-8.46 \mathrm{E}-04$ & $-8.60 \mathrm{E}-04$ & $-6.31 \mathrm{E}-04$ \\
A- PLA 3-1 & $-8.06 \mathrm{E}-04$ & $-9.13 \mathrm{E}-04$ & $-6.45 \mathrm{E}-04$ \\
A- PLA 4-1 & $-2.69 \mathrm{E}-05$ & $-4.03 \mathrm{E}-05$ & $1.34 \mathrm{E}-05$ \\
A- PLA 5-1 & $-2.69 \mathrm{E}-04$ & $-2.15 \mathrm{E}-04$ & $7.93 \mathrm{E}-04$ \\
\hline
\end{tabular}

Correlation coefficient higher than $\mathrm{R}^{2}=0.955$
Table 4 Values of $\chi_{23}^{\prime}$ calculated from Huang procedure for PEG composites

\begin{tabular}{llll}
\hline$\chi_{23}^{H}$ & $353 \mathrm{~K}$ & $363 \mathrm{~K}$ & $373 \mathrm{~K}$ \\
\hline A-PEG 1-1 & $-1.88 \mathrm{E}-05$ & $-1.41 \mathrm{E}-05$ & $-1.17 \mathrm{E}-05$ \\
A-PEG 2-1 & $-2.80 \mathrm{E}-05$ & $-2.18 \mathrm{E}-05$ & $-1.72 \mathrm{E}-05$ \\
A-PEG 3-1 & $-3.32 \mathrm{E}-05$ & $-2.59 \mathrm{E}-05$ & $-1.17 \mathrm{E}-05$ \\
A-PEG 4-1 & $-4.21 \mathrm{E}-05$ & $-3.27 \mathrm{E}-05$ & $-2.73 \mathrm{E}-05$ \\
A-PEG 5-1 & $-4.89 \mathrm{E}-05$ & $-3.95 \mathrm{E}-05$ & $-3.34 \mathrm{E}-05$ \\
\hline
\end{tabular}

Correlation coefficient higher than $\mathrm{R}^{2}=0.958$

value of $\chi_{23}^{Z C}$. The strongest interactions was shown for APLA 3-1 composite.

Huang's procedure

For all investigated compositions we also calculated $\chi_{23}^{\prime}$ parameterrs from the J-C. Huang procedure (Eq. 6). The obtained values are presented in the Tables 4 and 5 .

For both series of compositions we obtained negative values of the $\chi_{23}^{H}$ parameter. Compositions with PEG were characterized by smaller $\chi_{23}^{H}$ values than A-PLA. The lowest values were obtained for A-PEG 5-1 and A-PLA 5-1 compositions. In the Huang procedure, increasing the amount of the filler caused a decrease of the $\chi_{23}^{H}$ values.

The arrangement of the examined compositions according to the procedures proposed by Zhao-Choi and Huang is different. This is probably due to varying the volume used as 'reference' for calculation of $\chi_{1 \mathrm{~m}}$.

From values of $\chi_{23}^{\prime}$ calculated on the base of "soluteindependent" procedures, we can state that the best composition with the highest interaction between components is APLA 3-1 composition (the lowest value of $\chi_{23}^{Z C}$ ).

From $\chi_{23}^{H}$ values, it follows that the strongest interaction occurred for the A-PEG 5-1 composition.

In literature Flory-Huggins interaction parameter $\chi_{23}$ is usually presented as a ratio $\chi_{23} / v_{2}$ to discount the reference

Table 5 Values of $\chi_{23}^{\prime}$ calculated from Huang procedure for PLA composites

\begin{tabular}{llll}
\hline$\chi_{23}^{H}$ & $353 \mathrm{~K}$ & $363 \mathrm{~K}$ & $373 \mathrm{~K}$ \\
\hline A-PLA 1-1 & $-5.23 \mathrm{E}-07$ & $-4.09 \mathrm{E}-07$ & $-2.95 \mathrm{E}-07$ \\
A- PLA 2-1 & $-6.59 \mathrm{E}-07$ & $-4.55 \mathrm{E}-07$ & $-3.86 \mathrm{E}-07$ \\
A- PLA 3-1 & $-2.27 \mathrm{E}-07$ & $-4.55 \mathrm{E}-07$ & $-3.86 \mathrm{E}-07$ \\
A- PLA 4-1 & $-1.45 \mathrm{E}-06$ & $-1.09 \mathrm{E}-06$ & $-1.30 \mathrm{E}-06$ \\
A- PLA 5-1 & $-1.41 \mathrm{E}-06$ & $-1.61 \mathrm{E}-06$ & $-4.09 \mathrm{E}-07$ \\
\hline
\end{tabular}

Correlation coefficient higher than $\mathrm{R}^{2}=0.981$ 


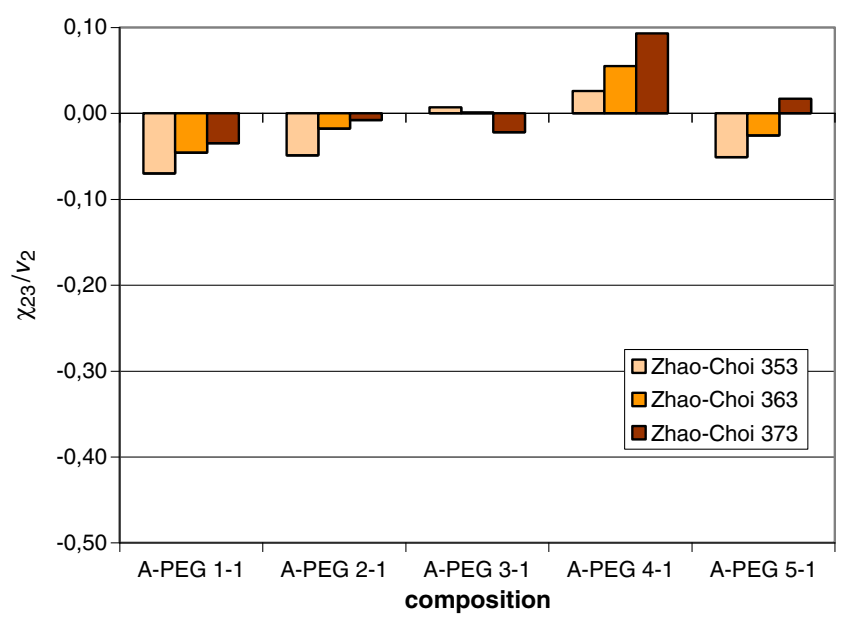

Fig. 5 Values of $\chi_{23} / v_{2}$ calculated from Zhao-Choi procedure for PEG compositions

volume value. In our case, values of $x_{22} / v_{2}$ for both procedures are presented in Figs. 5 and 6 (Zhao-Choi) or Figs. 7 and 8 (Huang).

For values obtained from the Huang procedure for both compositions, we can observe linear dependency from the amount of filler; for calculations from Zhao-Choi that dependence isn't linear.

The influence of the temperature was also observed. For APEG compositions an increase of the temperature causes an increase of the values of Flory-Huggins parameter $\chi_{23}^{\prime}$; whereas for A-PLA compositions the strongest interaction (the smallest $\chi_{23}^{\prime}$ values) were observed in the middle temperature independently from calculation procedure.

Which procedure is "better"? For those kinds of material, i.e., compositions of polymer with inorganic filler Huang's

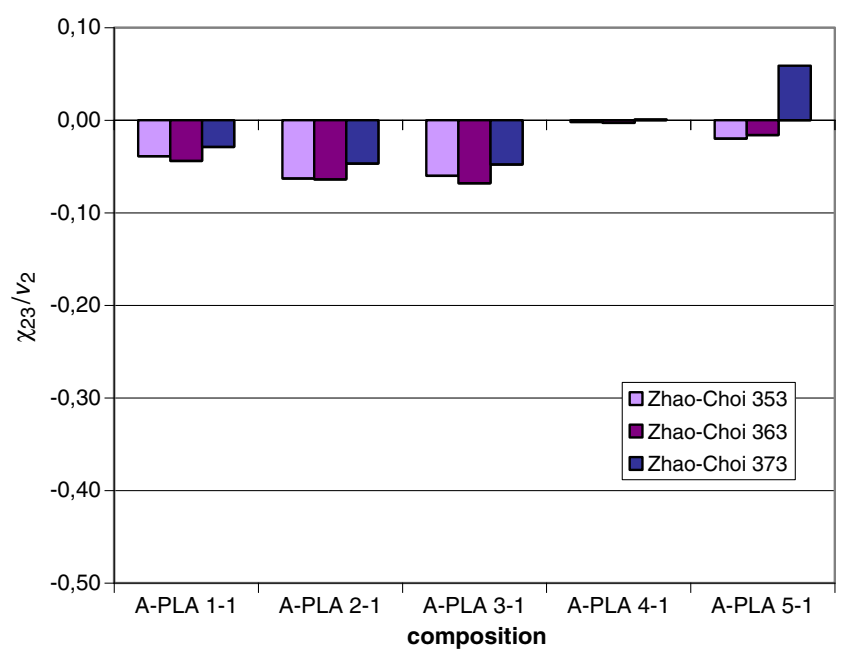

Fig. 6 Values of $x_{23} / V_{2}$ calculated from Zhao-Choi procedure for PLA compositions

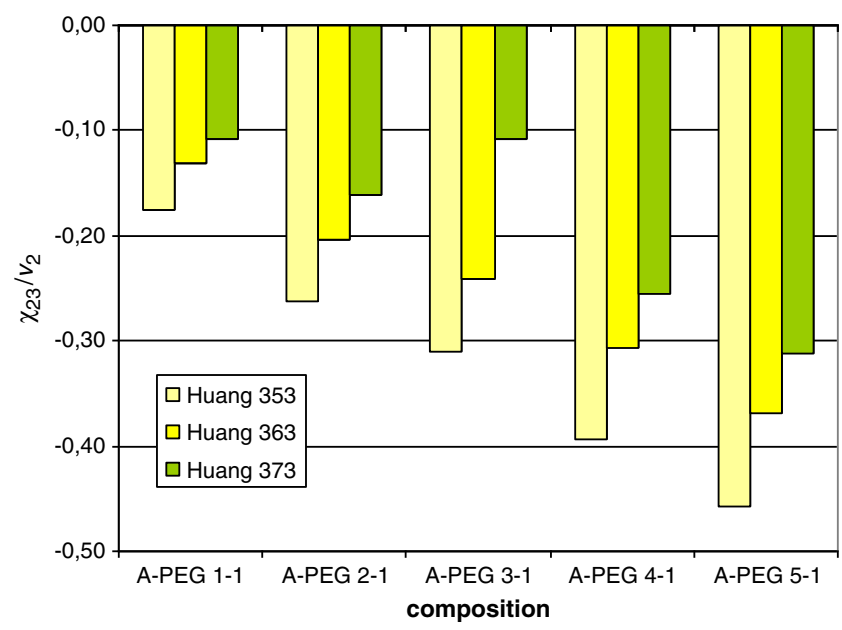

Fig. 7 Values of $x_{23} / v_{2}$ calculated from Huang procedure for PEG compositions

method seems to be more suitable. Values of $x_{22} / v_{2}$ calculated by the Huang method for both series of compositions are smaller than those obtained from the Zhao-Choi equation. This is more clear for interpretation of the strength of interaction (values $\sim 0$ may suggest existence of interaction or not). Linear dependence of $\chi_{23} / v_{2}$ values on the amount of the components is an additional advantage. It may facilitate the prediction of the magnitude of interactions in future investigations. However, the existence of such relationship should be confirmed for a larger group of investigated complex materials.

Results obtained by using standard and "solute-independent" Huang's procedures indicated strong interactions between components, as negative values of $\chi_{23}^{\prime}$ were found. Therefore, we suggest the use of the parameters determined

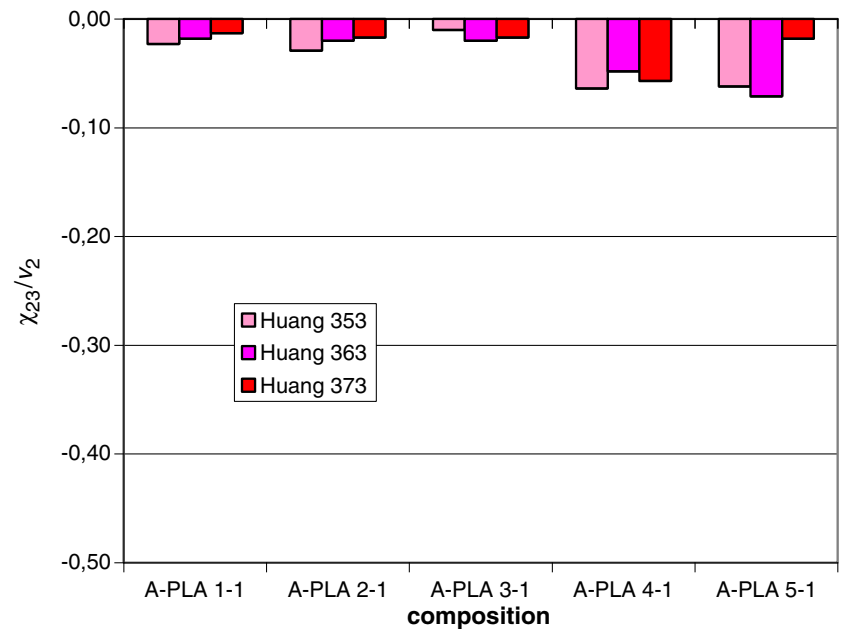

Fig. 8 Values of $x_{23} / v_{2}$ calculated from Huang procedure for PLA compositions 
by Huang's method in drawing conclusions on the properties of the examined complex polymeric systems.

\section{Conclusion}

The $I G C$ method was used for estimating the magnitude of interactions between the components of polymer compositions. Flory-Huggins parameters for polymer-filler systems were calculated using standard and "solute-independent" methods. Negative values of Flory-Huggins interaction parameter $\chi_{23}^{\prime}$ were found for almost all examined mixtures, which indicates significant interactions of the components used. It has been found that $\chi_{23}^{\prime}$ values depend on the nature of the test solute used in the $I G C$ experiment. Stronger interactions were observed for the A-PEG composition (lower values of $\left.\chi_{23}^{\prime}\right)$. Application of Zhao-Choi and Huang procedures leads to elimination of solute dependence of $\chi_{23}^{\prime}$. Values $\chi_{23} / v_{2}$ obtained from Huang procedure for both compositions depend linearly on the amount of filler. By using $\chi_{23} / v_{2}$ values, one may follow the changes in the magnitude of interactions between the components of the composition resulting from the changes of filler properties, its amount and temperature.

Open Access This article is distributed under the terms of the Creative Commons Attribution License which permits any use, distribution, and reproduction in any medium, provided the original author(s) and the source are credited.

\section{References}

1. Al-Saigh ZY (1997) Int J Polym Anal Charact 3:249

2. Al-Saigh ZY, Guillet J (2000) "Inverse gas chromatography in analysis of polymers and rubbers", invited chapter. In: Meyers R (ed) Encyclopedia of analytical chemistry: instrumentation and applications. Wiley, Chichester, pp 7759-7792

3. Fall J, Milczewska K, Voelkel A (2001) J Mater Chem 11:1042

4. Zhao L, Choi P (2001) Polymer 42:1075

5. Zhao L, Choi P (2002) Polymer 43:6677

6. Milczewska K, Voelkel A, Jęczalik J (2003) Macromol Symp 194:305

7. Milczewska K, Voelkel A (2006) J Polym Sci B Polym Phys 44:1853

8. Al-Saigh ZY (1997) TRIP 5:97

9. Fernandez-Sanchez E, Fernandez-Torres A, Garcia-Dominguez JA, Santiuste JM, Pertierra-Rimada E (1988) J Chromatogr 457:55

10. Deshpande DD, Patterson D, Schreiber HP, Su CS (1974) Macromolecules 7:530

11. Su CS, Patterson D (1977) Macromolecules 10:708

12. Farooque AM, Deshpande DD (1992) Polimer 33:5005

13. Huang J-C (2003) J Appl Polym Sci 90:671

14. Huang J-C, Deanin RD (2004) J Appl Polym Sci 91:146

15. Milczewska K, Voelkel A (2012) Inverse gas chromatography in characterization of composites interaction. In: Mohd MA (ed) Advanced gas chromatography - progress in agricultural, biomedical and industrial applications. ISBN: 978-953-51-0298-4, pp. 421-436 InTech

16. Huang J-C (2011) J Appl Polym Sci 119:719

17. Milczewska K, Voelkel A (2008) Mater Sci Forum 587-588:667

18. Milczewska K, Voelkel A (2008) J Appl Polym Sci 107:2877

19. Product information Aerosil ${ }^{\mathbb{R}} 200 \mathrm{~V}$ - Evonic Industries AG, June 2012 